\title{
Corpo de mulher: a trajetória do desconhecido na Bahia do século XIX
}

\author{
Renilda BARRETO*
}

\begin{abstract}
RESUMO
Este trabalho, de natureza historiográfica, pretende discutir a forma de organização do saber médico na Bahia do século XIX em torno do corpo feminino. Este período revela a emergência do saber médico, fundamentado no espírito de cientificidade oitocentista, em contraposição às práticas seculares de curas, respaldadas no saber popular. $\mathrm{O}$ texto foi produzido a partir das consultas a fontes primárias, tais como as publicações da Gazeta Médica da Bahia, jornais e periódicos de circulação em Salvador, no período em questão; Memórias Históricas da Faculdade de Medicina; teses de conclusão de curso; os discursos proferidos na Câmara Municipal; relatórios médicos da Santa Casa de Misericórdia de Salvador, dentre outros documentos reveladores da construção do saber médico na Bahia do século XIX. A análise aqui desenvolvida está ancorada na história social da medicina e do corpo.

Palavras-chave: história do corpo, medicina, mulher.
\end{abstract}

\begin{abstract}
This historical study aims at the discussion about how medical knowledge of the female body was organized in Bahia in the $19^{\text {th }}$ century. That period reveals the emergence of medical knowledge based on the scientific spirit of the 1800's as opposed to old healing practices supported by popular perceptions. The text was produced from research into primary sources such as issues of Gazeta Médica da Bahia (Medical Journal of Bahia) and periodicals available in Salvador during that time; Memórias Histórias da Faculdade de Medicina (Medical School Historical Memories); graduation theses; speeches given to the City Counsil;
\end{abstract}

* Professora do Centro Federal de Educação Tecnológica de Salvador, Bahia. Mestra em História pela Universidade Federal da Bahia. 
medical reports from Santa Casa de Misericórdia (a charity institution) in Salvador, among others. These documents show how medical knowledge was constructed in Bahia in the $19^{\text {th }}$ century. The analysis is based on social history of medicine and the body.

Key-words: history of the body, medicine, women.

Em 1950, a parteira Melânia Margarida dos Santos, residente em Coutos, subúrbio de Salvador, falando sobre a hora do parto, aconselhava a mulher acometida pelas dores que se sentasse em cozimento de mentastro branco ou Vassorinha de Nossa Senhora, já que ambas amoleciam a junta do "eixo". ${ }^{1}$ A água desse banho deveria estar mais para morna do que para quente. Caso não tivesse as folhas, deveria bater um bocado de sabão virgem dentro da água quente até aparecer espuma e fazer uso, pois tinha o mesmo efeito que o mentastro. Se as dores começassem longe de casa, a grávida deveria colocar uma pedra na cabeça e seguir viagem, pois a pedra evitava o nascimento da criança. "Sendo a parturiente devota de Nossa Senhora do Parto ou de São Raimundo poderia ficar descansada que de parto não morreria e as dores seriam mais suaves." ${ }^{2}$

Melânia tinha horror aos médicos e aos remédios de farmácia que estragavam o estômago. Criticava as "melúrias" dos doutores que inventavam coisas nunca vistas, tais como menino andar sem barrete, não enfaixar o umbigo do recém-nascido e nem apertar a barriga da mulher parida. ${ }^{3}$

A fala da parteira Melânia é um convite para se adentrar no universo de investigação sobre os construtos culturais e históricos que envolveram o corpo feminino e suas funções especificamente biológicas, tais como menstruação, gravidez, parto e seus desdobramentos. É uma investigação que revela um conjunto de símbolos representativos de uma sociedade que

1 Seccionamento da sínfise púbica.

2 VIANNA, H. As aparadeiras e sendeironas: seu folclore. Salvador: Centros de Estudos Baianos da Universidade Federal da Bahia, 1988. p. 20-22. A folclorista Professora Hildegardes Viana coletou depoimento de parteiras que atuaram em Salvador na primeira metade do século XX. Em nosso trabalho, exploramos os depoimentos destas aparadeiras, na perspectiva da longa duração, pois aquelas práticas de partejamento estiveram muito próximas das empregadas pelas parteiras do século XIX.

3 Ibid., p. 10. 
demarcou formas de compreensão em torno da mulher, do seu corpo e dos mecanismos de manipulação deste.

Esta perspectiva de investigação histórica transita na interface da história das mulheres, do corpo e da medicina, ancorada nas abordagens da história social e cultural. A análise das diversas formas de parturição, que estiveram presentes no cotidiano da população de Salvador no século XIX, permite uma leitura das representações culturais que envolveram parteiras, médicos e parturientes. Estas imagens são reveladas pelo explícito e pelo oculto, extraídas das linhas e entrelinhas das fontes documentais. O implícito pode não ser visível num primeiro olhar, mas é, todavia, perceptível e significativo a ponto de dar voz àquelas pessoas que se ocuparam durante muitos séculos da cultura do corpo.

O estudo das temáticas, relacionadas ao corpo, à medicina e à história, vem ganhando rapidamente os espaços acadêmicos e, conseqüentemente, as pesquisas nas mais diversas áreas do conhecimento, isto porque há uma preocupação em redimensionar não só o objeto de pesquisa como também a sua abordagem. O corpo passa a fazer parte do contexto social, deixando de ser privado das áreas médicas e passando a fazer parte da seara do historiador.

O corpo passa, pois, a interessar ao historiador como espaço constitutivo de laços sociais. Seus atos, gestos e práticas são elementos de uma cultura, retratam sistemas de valores específicos, organizam um modo de vida.

(...) Por meio das palavras, o corpo se constrói e desconstrói infatigavelmente, num complexo jogo de equivalências e correspondências, de transbordamentos e de nivelamentos. É nesta linha fronteiriça que as imagens da vida interior/exterior do corpo ganham sentido. ${ }^{4}$

Nos tempos medievais e modernos, o corpo não existia dissociado do espírito, sendo esta via o portal de entrada e saída das doenças. As técnicas e os rituais empregados para combater as enfermidades nem sempre

4 DEL PRIORE, M. Dossiê: a história do corpo. Anais do Museu Paulista, São Paulo, v. 3, p. 14 - 15, jan./dez. 1995. 
alcançavam o resultado almejado, mas eram legitimados por um saber corrente na sociedade, onde as explicações perpassavam pelas crenças espirituais. Esta cultura da cura materializava-se nos lares, nas igrejas, nas tavernas, nas ruas, nos campos, através do uso de amuletos, poções mágicas, adivinhações, milagres de reis e de santos, profecias, beberagens feitas com ervas e com objetos encantados, benzeduras, dentre outras práticas.

Neste contexto, eivada por representações medievais, a mulher era um ser naturalmente impuro e pecaminoso e tinha como função primordial a procriação. O seu corpo era o espaço de lutas entre Deus e o diabo, portanto estavam, as mulheres, sujeitas a afecções, a exemplo da menstruação, parturição, gravidez, corrimentos, dentre outros, apenas explicáveis pela escatologia medieval. A partir do final do século XVIII, estes seres licenciosos precisavam ser conhecidos nas suas entranhas para que fossem submetidos a uma normatização, sendo, assim, esvaziados de todo e qualquer poder que ameaçasse a ordem dominante. Os aspectos inerentes ao universo feminino, incompreendidos na sua quase totalidade, tais como prenhez, parturição e cura de moléstias, deveriam ser conhecidos e controlados por outra esfera do saber: de preferência a dos homens da ciência.

A partir do século XVIII, porém, o olhar médico obstetra começa a devassar um ritual que era vivenciado por uma comunidade exclusivamente feminina: o momento do parto, um saber transmitido de mães para filhas, que reunia parturiente, parteira, comadres e vizinhas, numa união calorosa entre o público e o privado. ${ }^{5}$

Os processos terapêuticos a que era submetido o corpo feminino mantinham uma relação intrínseca e atemporal com o mundo sobrenatural. Por exemplo, a dor de "dar a luz" era um padecimento necessário, pois, nesta hora, a mulher purgava parte de seu pecado original e aproximava-se da Virgem Maria, Mãe de Jesus. Ao findar o período do puerpério, ${ }^{6}$ retomando sua condição de filha de Eva, a mulher era novamente revestida dos estere-

5 DEL PRIORE, M. A mulher na história do Brasil. São Paulo: Contexto, 1994. p. 51.

6 Período pós-parto. 
ótipos correntes na sociedade, isto é, a pecadora, traidora, lúgubre, visto que as práticas sexuais para as mulheres eram permitidas com intuito único de procriação, sendo o prazer considerado como pecado.

A construção desta imagem de mulher pode ser localizada na Idade Média, onde os teólogos professavam que Eva era uma projeção da criação divina por ter sido originada a partir da costela de Adão e não da imagem de Deus. Este ser imperfeito, chamado mulher, podia levar o homem à danação por isso era considerada infiel, fútil, inconstante, astuciosa e perigosamente sensual. O pecado da luxúria esteve no centro das preocupações e das reprovações sociais até poucas décadas atrás. ${ }^{7}$

O raiar do século XIX traz consigo as discussões travadas pelos iluministas, ao tempo em que acrescenta outras considerações sobre a anatomia feminina, fruto dos estudos da medicina, da anatomia e da fisiologia, em franco desenvolvimento na Europa e, também, no Brasil. Os centros urbanos no século XIX disseminaram gradativamente a autoridade médica no que tange à saúde pública e estes guardiões da vida, da moral e dos costumes tornaram-se também baluartes da nação. ${ }^{8}$

Nos livros e teses escritos por homens, o corpo feminino parece uma cidadela a ser submetida às regras do novo saber: a medicina. Deste corpo escapam tantos segredos que é absolutamente necessário reduzi-lo e adestrá-lo. Por trás da idéia de um corpo que é também terra desconhecida, cartografia ilegível a ser devassada pelo conhecimento objetivo, existe igualmente o reconhecimento do corpo enquanto uma potência que desafia as argúcias do saber mesmo quando ele chega a compreender as obscuridades da fisiologia feminina. ${ }^{9}$

7 Ver DUBY, G. Damas do século XII: a lembrança dos ancestrais. São Paulo: Companhia das Letras, 1997; MACEDO, J. R. de. A mulher na Idade Média. São Paulo: Contexto, 1997; FRANCO JÚNIOR, H. As utopias medievais. São Paulo: Brasiliense, 1992.

8 Ver REIS, J. J. A morte é uma festa: ritos fúnebres e revolta popular no Brasil do século XIX. São Paulo: Companhia das Letras, 1991; SCHWARC, L. M. O espetáculo das raças: cientistas, instituições e questão racial no Brasil - 1870-1930. São Paulo: Companhia das Letras, 1993.

9 DEL PRIORE, M. História das mulheres: as vozes do silêncio. In: FREITAS, M. C. (Org.). Historiografia brasileira em perspectiva. São Paulo: Contexto, 1998. p. 230. Cf. DEL PRIORE, M. A árvore e o furto: um breve ensaio histórico sobre o aborto. [S. 1.: s. n.], 2000. p. 5. 
Emerge a racionalização científica oitocentista que aparta o doente da doença e, através de teorias, conceitos e leis, passam a fomentar um modelo explicativo para a vida e morte do corpo, construindo, assim, uma nova ordem das representações médicas enquanto saber cientificamente elaborado. O corpo é visto como o locus da doença, e esta é explicada objetivamente, passando o profissional da cura a exercer, junto ao doente e à sociedade um certo tipo de poder, onde o indivíduo se via afastado da sua corporeidade, visto que esta passava a ser de domínio do médico.

A coincidência exata do "corpo" da doença com o corpo do homem doente é um dado histórico e transitório. Seu encontro só é evidente para nós, ou melhor, dele começamos a nos separar. O espaço de configuração da doença e o espaço de localização do mal no corpo só foram superpostos, na experiência médica, durante curto período: o que coincide com a medicina do século XIX e os privilégios concedidos à anatomia patológica. Época que marca a soberania do olhar, visto que no mesmo campo perceptivo, seguindo as mesmas continuidades ou as mesmas falhas, a experiência lê, de uma só vez, as lesões visíveis no organismo e a coerência das formas patológicas; o mal se articula exatamente com o corpo e sua distribuição lógica se faz, desde o começo, por massas anatômicas. O "golpe de vista" precisa apenas exercer sobre a verdade, que ele descobre no lugar onde ela se encontra, um poder que, de pleno direito, ele detém. ${ }^{10}$

No Brasil - da Colônia até a República -, a mulher e o seu corpo eram compreendidos e explicados a partir de um quadro mental muito semelhante ao da Europa, visto que a Colônia herdou muito da cultura cristã européia. Isto significa dizer que bem pouco se conhecia dos mistérios do feminino, pois a ciência médica do Brasil colonial também estava impregnada pelo imaginário da dramaturgia feminina, onde as doenças, o aborto, $o$ parto e a morte eram resultados dos defeitos, excessos ou normalidade de suas próprias fisiologias. ${ }^{11}$ Ciclos menstruais, gravidez, parto, amamentação,

p. 1-2.

10 FOUCAULT, M. O nascimento da clínica. Rio de Janeiro: Forense Universitária, 1998.

11 DEL PRIORE, M. Ao sul do corpo: condição feminina, maternidade, e mentalidade no Brasil Colônia. Rio de Janeiro: José Olympio, 1993. 
constituição do aparelho geniturinário feminino e as doenças de mulheres, oriundas do mundo físico ou espiritual, demarcaram fronteiras de conhecimento a serem desbravadas pelos médicos no Brasil e alhures.

A partir da fundação das Escolas de Medicina da Bahia e do Rio de Janeiro (1808), caberá aos médicos a missão civilizadora, que iria romper com o passado colonial, extirpando todo e qualquer elemento que pudesse caracterizar o Brasil como nação "atrasada". Mas o que era a ciência médica para o Brasil do século XIX? O quanto esta se afastava das crenças de outrora e como a população a recebia? Será a medicina dos médicos, "o thesouro da sabedoria"? E o médico, "um anjo homem"? Ou continuava valendo a recomendação da beata de Braz Luis de Abreu que dizia "não se fie nos médicos humanos, hão de matar Vossa Mercê com purgas e xaropes"12?

\section{O olhar dos médicos}

Mapeando a geografia do corpo feminino, Mary Del Priore apresentou a compreensão da medicina lusitana sobre órgãos do aparelho reprodutor feminino, tais como os ovários, trompas de Falópio, útero e vulva, recorrentes nos compêndios, manuais e tratados da medicina dos séculos XVII e XVIII, nos quais concepções religiosas e supersticiosas, se mesclavam à produção de conceitos anatômicos, nosológicos, morais e metafísicos, próprios da "natureza feminina". ${ }^{13}$

Acreditava então, a medicina portuguesa que a madre ${ }^{14}$ estava no centro do complexo emaranhado que constituía o organismo feminino e governava despoticamente os humores femininos. A madre tinha finalidade procriativa, alimentava-se de sangue e pneuma,${ }^{15}$ era fria, seca, provida de pilosidade no interior e dividida em compartimentos. ${ }^{16}$ Para Antonio

12 Cf. DEL PRIORE, A árvore..., op. cit.

13 DEL PRIORE, Ao sul do..., op. cit.

14 O mesmo que útero.

15 Essência espiritual invisível e inatingível, de difícil conceituação uma vez que mistura noções religiosas, filosóficas e científicas.

16 DEL PRIORE, Ao sul do..., op. cit., p. 206-207. 
Ferreyra em Luz verdadeyra de 1705, a madre era "hüa parte ordenada da natureza em as mulheres, principalmente para receber o semen. \& delle se engendrar a creatura para conservação do genero humano..."17

Nesta estranha geografia do corpo feminino, os ovários estavam localizados no fundo do útero, segundo Santos de Torres no Promptuario Pharmaco, e Cirúrgico de 1756, onde "entre os ligamentos largos se achão aquelles corpos visiculares mais ou menos grossos, dous dedos afastados, e aos quaes os antigos chamavão testiculos femininos, e os modernos chamão ovários."18

A madre era capaz de provocar na mulher uma série de males, desencadear uma quantidade de enfermidades que variava da loucura a ninfomania. Esta crença de que o útero era determinante dos humores da mulher fez eco até depois da segunda metade do século XIX entre os médicos baianos. O formando em medicina, pela Faculdade de Medicina da Bahia, Manuel Caludino Ribeiro prescreve em sua tese - Considerações acerca do abortamento - que para conter a irritabilidade do útero nas mulheres grávidas são indicados os banhos mornos, sangrias, ópio e um regime moderado "a fim de combater este estado do orgão." 19

Apesar do relativo avanço da medicina no século XIX, a partir da tecnologia de laboratório, identificação de bactérias causadoras de doenças e sua forma de transmissão, os médicos baianos continuaram conhecendo pouco sobre o corpo feminino e a "sufocação da madre". Inúmeras foram as teses sobre o abortamento no século XIX produzidas pelos formandos da Faculdade de Medicina, quase todas elas pautadas nas experiências e dados dos obstetras franceses, denominados nestas teses de parteiros. Todavia, uma chama atenção pelos dados referentes ao grau de conhecimento dos médicos no Brasil. O graduando Benjamim Constant Pereira fez considerações acerca do abortamento e afirma que:

17 Citado em SÃO PAULO, F. Linguagem médica popular no Brasil. Salvador: Itapuã, 1970. v. 2, p. 223-224.

18 Ibid., p. 223.

19 RIBEIRO, M. C. Considerações acerca do abortamento. In: Memorial de medicina brasileiro. Bahia: Imprensa Econômica, 1883. p. 22. (These defendida na Faculdade de Medicina da Bahia). 
Não se poderá chegar facilmente a obter sobre este ponto dados positivos, porque a maior parte dos abortamentos ficam ignorados pelos médicos ou ainda que é sobretudo a proposta das causas do abortamento que a imaginação tem dado vôos. (...)

Em grande numero de casos, a natureza intima do acidente nos escapa; é preferivel confessar nossa ignorancia, que recorrer á explicações pueris que não resistem ao exame serio. ${ }^{20}$

Perpetuavam-se, assim, as crenças medievais e modernas de que a gravidez e a maternidade tinham uma função reguladora da saúde do corpo feminino e o sêmen, poder curativo, como afirmou o doutorando Raulino Francisco de Oliveira Junior sobre este tema: “A gravidez é, às vezes, causa de certas molestias que a parturição pode modificar, ou fazel-as suspender e mesmo desapparecer." 21

A definição da "natureza feminina" pela medicina baiana oscilava entre a patologia clínica e os valores morais e religiosos vigentes na cultura local, sendo o casamento considerado como um "santo remédio" para as crises de histeria e o furor interno:

Quase todos os praticos são accordes em considerar as affecções hystericas, que se manifestão nas virgens e nas viuvas, como consequencia da privação do casamento. Com efeito é de intuição [grifo nosso], que as mulheres, principalmente bem casadas, são ordinariamente isenptas de taes affecções, ao passo que ellas são muito communs nos lugares onde existe o voto de castidade, por exemplo, nos conventos.

(...)

De tudo se pode deduzir a importancia que tem o casamento, apenas considerando como o melhor meio de favorecer e determinar a excreção do semen; ambos os sexos gosão das suas vantagens, e é só neste estado que a saude pode ser completa.

20 PEREIRA, B. C. Considerações acerca do abortamento. In: Memorial de medicina brasileiro. Bahia: Typographia dos Dous Mundos, 1885, p. 4-6. (These defendida na Faculdade de Medicina da Bahia).

21 OLIVEIRA JUNIOR, R. F. de. Indicações e processos operatórios do parto prematuro artificial. In: Memorial de medicina brasileiro. Bahia: Typograpfia do Diário, 1873. p. 19. (These defendida na Faculdade de Medicina da Bahia). 
O casamento influe a tal ponto sobre a saude, que se elle é moderado muito contribue para tornal-o a florecer e conservalo por muito tempo..$^{22}$

A princípio a terapêutica das doenças era uma constante tentativa de erro e acerto, partindo da farmacopéia local, dos compostos químicos manipulados pelos boticários ou dos remédios importados da Europa. Até mesmo para os doutos das Faculdades de Medicina, a tarefa de salvar vidas era extraordinária e para estes, muitas vezes, só restava dar conforto espiritual àqueles que aguardavam um certeiro encontro com a morte.

Não desanimeis, por isso, moços. Mergulhai o vosso espírito nessas águas reconfortantes e inspiradoras; oferecei delas aos vossos enfermos, para que estanquem a sua sede; e não desanimeis, ainda quando o vosso escasso saber frustrar a vossa vontade, quando os vossos remédios não puderem curar! A medicina não é somente o diagnóstico e a arte de formular. Ela é também a caridade (...)

Se não vos for dado curar, aliviar a dor e o sofrimento.Isso já é obra divina! E quando nem mesmo isso estiver ao vosso alcance, quando ciência falhar de todo, que a caridade ainda vos inspire. Não abandoneis esse pobre náufrago que se agarra à vida, esse miserável condenado que depositou, em vós, todas as suas esperanças. Enganai-o! menti-lhe! Mas consolai-o! ${ }^{23}$

Quando acometidos por alguma enfermidade, a população baiana preferia recorrer as meizinhas, ${ }^{24}$ deixando para última instância a procura de um médico. Ao analisar a terapêutica empregada no tratamento das doenças de mulheres, observamos que não há grandes diferenças entre a nosologia

22 LISBOA, F. A. da S. Hygiene da mulher em estado de gravidez. In: Memorial de medicina brasileiro. Bahia: Typographia de Camillo de Lellis Masson \& C., 1870. p. 12. (These defendida na Faculdade de Medicina da Bahia).

23 OLIVEIRA, O. de. O fetichismo terapêutico e a medicina moderna. In: VIANNA, G. Olinto de Oliveira. Porto Alegre: Globo, 1945. p. 45.

24 Remédios populares para curar os males que atacam o organismo. 
dos médicos e das comadres ${ }^{25}$ durante o século XIX. O tratamento de ambas as modalidades de cura estava pautado no desconhecimento da etiologia, no emprego da farmacopéia local e das meizinhas.

Sabe-se que a medicina pouco ou quase nada intervinha no aparelho geniturinário feminino. As enfermarias femininas da Santa Casa de Misericórdia foram os laboratórios dos primeiros experimentos cirúrgicos para médicos e estudantes, sem auxílio de qualquer anestésico, ou quando muito do ópio, sem a higiene adequada e realizada com aparelhos rudimentares a ponto de impressionar os próprios médicos. "A operação não foi de modo algum difficultosa, mas horrivelmente feia; e julgo que nada poderia parecer mais medonho do que o aspecto da paciente depois d'ella [a cirurgia] terminada." 26

Para opções de cura das doenças os homens, mulheres e crianças que não possuíam recursos nem família, a opção era procurar ajuda na Santa Casa de Misericórdia da Bahia. Das mulheres que recorreram ao hospital da Santa Casa de Misericórdia, único a atender a população até 1759, ano de fundação do hospital militar, destacam-se as pobres, presas, escravas e desvalidas.

Eram aquelas despossuídas de bens materiais ou de condição social, entregues à própria sorte que recorreram à caridade das Irmãs da Santa Casa, ficando à disposição do olhar clínico dos médicos e do aprendizado dos alunos da Faculdade de Medicina.

A enfermaria de S. João recebe também quase sempre mulheres velhas, decrepitas, idiotas e mendigas, que, conquanto entre com molestias, às vezes, incuraveis, o Hospital não pode deixar de recebe-las, uma vez que estas infelizes completamente abandonadas à miseria e ao infortunio, procuram este asilo da caridade como refugio onde se abriguem. ${ }^{27}$

25 O termo comadre, muito utilizado nas comunidades rurais da Península Ibérica e do Brasil, designa parteira prática, sem diploma. Percebe-se que no discurso médico baiano de final de século XIX, a expressão é nitidamente depreciativa.

26 GAZETA MÉDICA DA BAHIA. Salvador, ano 11, n. 1, p. 6, jan. 1879

27 SANTA CASA DE MISERICÓRDIA DA BAHIA. Relatórios de 1871. Bahia, mapa 3. 
Emais:

Este estabelecimento é, por assim dizer, no genero, o refugio e abrigo unico da população pobre desta Capital; porque, de portas sempre abertas há todos quantos se apresentão com attestações de autoridades policiaes, agentes consulares e outras, nenhuma recusa manifesta aos desvalidos que o procurão. ${ }^{28}$

Outros documentos trabalhados na Santa Casa de Misericórdia, em especial os livros de Assento, corroboram com este mosaico social esboçado pelos Relatórios:

Maria de Tal, branca, alienada, não falla couza alguma em termos, remettida com offico pelo Dr. Chefe de Policia. São João [enfermaria]

Moléstia: Maluca. Sahaio curada a 15 de $9 \mathrm{br}^{\circ}$ de 1852

Maria dos Santos, Preta, 76 annos, solteira, Africana, liberta, Angola, mendiga, moradora a Saude, entrou com atestado do Subdelegado de $\mathrm{St}^{\mathrm{a}}$ Anna, entregou Carta de Liberdade. Enfermaria de São João.

Molestia: Velhice e Desenteria. Falleceo ao $1^{\circ}$ de março de 1853.

Henriqueta, preta, 20 annos, solteira, africana livre, servente do Hospital, entrou por ordem do Administrado do mesmo. Enfermaria da Assumpção.

Molestia: Bronquite. Sahio curada aos 5 de março de 1853.

Cândida Maria da Conceição, 22 annos, parda, de Jaguaripe, solteira, costureira, e moradora á S. Pedro Velho. Por attestado do Subdelegado de São Pedro Velho. Assumpção [enfermaria]. Molestia: Hepatite. Falleceo em 30 de agosto de 1853.

Ursula Ferreira, Branca, 30 annos, da Bahia, cazada com Bento Jozé Ramos, costureira, moradora á ladeira da Soledade. Por attestado do Subdelegao de $\mathrm{St}^{\circ}$ Antonio Alem do Carmo. 


\author{
Assumpção 2a [enfermaria] \\ Molestia: Cancro uterino. Falleceo aos 24 de $8 b^{\circ}{ }^{\circ}$ de 1853. \\ Gertrudes Ritta da Conceição, 24 annos, crioula, da Bahia, \\ solteira, vive d'allugar-se, moradora á Saúde. Veio á porta. \\ Assumpção $1^{\text {a }}$ [enfermaria] \\ Molestia: Diarrhea. Falleceo em 7 de maio de 55. ${ }^{29}$
}

Dentre as principais doenças que atingiram aquelas mulheres que procuraram a Santa Casa de Misericórdia entre 1845-1852 estavam: a sífilis, a úlcera, a blenorréia, o cancro venéreo, a tuberculose, a febre intermitente, a varíola, a desinteria, a diarréia, a erisipela, a pneumonia, a gangrena, a hepatite, o reumatismo, as hemorróidas, a paralisia, a apoplexia e as doenças mentais. ${ }^{30}$

O quadro nosológico não era muito diferente no final do século, entre os anos de $1881-1883,{ }^{31}$ período em que foram atendidas 2.800 pessoas na Santa Casa de Misericórdia, sendo 441 crianças, 1470 homens e 889 mulheres, das quais 29 eram escravas. Persistiam as doenças já citadas, acrescidas de beribéri, febre perniciosa, insuficiência, úlcera sifilítica, epilepsia, tubérculos pulmonares, tétano, dentre outras. ${ }^{32}$ Nesse mesmo período, das 889 mulheres atendidas pelo hospital da Santa Casa, 302 eram pardas, 254 eram pretas, 192 brancas, 49 creolas e 09 cabras. Dentre as atividades profissionais declaradas nos prontuários predomina as de servente e costureira. ${ }^{33}$ Estes dados refletem uma cidade efervescente nas suas atividades laborais, especialmente nas ocupações femininas, bem como evidencia uma hierarquia social pautada em valores diversificados. ${ }^{34}$

1855).

29 SANTA CASA DE MISERICÓRDIA DA BAHIA. Livro 19 de assentos de pessoas (1852-

30 ATHAIDE, J. L. de. La Ville de Salvador au XIXe Siècle - aspects démographiques. Paris, 1975. Tese (Doutorado), L'Université de Paris X.

31 O período escolhido para esta análise quantitativa (1881-1883) constituiu-se numa tentativa de mapear as doenças que levaram a óbito na segunda metade do século XIX, já que os estudos de Johildo L. de Athaide foram referentes à primeira metade do século citado.

32 SANTA CASA DE MISERICÓRDIA DA BAHIA. Fonte H/Base/1377, 1881-1883.

33 Id.

34 Ver SOARES, C. M. Mulher negra na Bahia do século XIX. Salvador, 1994. Dissertação (Mestrado em História) - Faculdade de Filosofia e Ciências Humanas, Universidade Federal da Bahia. PONTES, K.V. Mulatos: políticos e rebeldes baianos. Salvador, 2000. Dissertação (Mestrado em História) - Faculdade de Ciências Humanas, Universidade Federal da Bahia. 
O Dr J. L. Paterson, da já citada Escola Tropicalista Baiana, ao fazer o relato das cirurgias realizadas em mulheres afirmou que:

\begin{abstract}
...neste paiz, ou, pelo menos, n'esta cidade são freqüentissimos os fibroides do utero em forma de polypo, de tumores pendentes de sua superficie externa, ou entranhados em sua substancia, ao passo que os kystos do ovario, tão freqüentes em alguns paizes europeus, que constituem uma especialidade per se, muito pouca vezes se encontra aqui. ${ }^{35}$
\end{abstract}

Constata-se que o número de homens atendidos na Misericórdia foi maior que o de mulheres para o período analisado (1881/1883). Será que aqueles adoeciam mais que estas? Ou estas se mantinham na privacidade de seu lar, desfrutando do tratamento realizado por outras mulheres? Será que as enfermarias da Santa Casa de Misericórdia inspiravam confiança?

Analisando o depoimento do Dr. Custodio Moreira, pode-se compreender porque a população da cidade de Salvador, sobretudo as mulheres pejadas, desconfiava dos cuidados médicos e cultivava a crença de que a morte rondava de perto as enfermarias da Misericórdia:

\footnotetext{
Existe uma sala n'este hospital destinada às parturientes.

É uma sala pequena, sem ventilação nenhuma, n'um foro miasmatico junto das enfermarias, sem uma só condição higienica!

Esta sala, ou melhor, este necroterio, raramente é arejada.

Por estas condições desfavoraveis, pela falta de prescripções higienicas, que põe sempre em risco a vida da mulher como a da criança, ela é pouco procurada.

Fora melhor não existir.

Eis a lugubre sala da maternidade do triste hospital da Misericordia! ${ }^{36}$
}

35 PATERSON, J. L. Gazeta Médica da Bahia. Salvador, ano 10, n. 5, p. 202, maio 1878.

36 SOUZA JÚNIOR, C. M. de. Histórico dos hospitais e maternidades. Bahia: Imprensa Econômica, 1886. p. 16. 
Na ausência do médico por carência numérica destes profissionais, pelo custo monetário do tratamento especializado, ou ainda, por opção, as mulheres baianas preferiam o diagnóstico e a cura das enfermidades realizadas por outras mulheres, principalmente no que diz respeito às doenças exclusivamente femininas: pólipo uterino, "fysto", ulceração interna, doenças do útero, "excitação nervosa", sífilis, úlcera sifilítica, blenorréia, cancro uterino, febre puerperal etc. ${ }^{37}$

Esta preferência das mulheres, na cura das enfermidades por outras mulheres, levou o Dr. J. Cândido, em sua Synopse das Moléstias que mais reinão na cidade de S. Salvador, na primeira metade do século XIX, a fazer o seguinte desabafo:

Os chancros uterinos, as ulcerações do collo e os polypos não são raras na Cidade da Bahia: diremos até, que são muito communs - as nossas patricias por um pudor mal entendido sentem-se adoecer - e occultão o seo padecimento, muita vez, até do proprio marido - mais tarde mandão chamar a uma comadre, que ordinariamente lhes aggrava o mal - enfim quando a doença tem estragado grandemente o organismo, quando talvez já não he curavel, pedem um Medico, para carregar com o anathema d'ellas e de suas familias; porque não curou uma molestia já incuravel - e sobre a qual por muito tempo especulou a indigna - comadre. - Indubitavelmente as affecções do utero na Bahia são causadas pela vida sedentaria, que leva o sexo das graças entre nós.

A hysteria, os ataques epileptiformes, as palpitações, a melancolia, os faniquitos, muita vez, fingidos e algumas outras neuroses ainda são doenças não raras entre as bahianas. ${ }^{38}$

37 No período de abrangência da pesquisa (1832-1889) graduaram-se pela Faculdade de Medicina da Bahia 1.955 médicos. Cf. MEMORIAL de medicina brasileiro. Índice dos Graduados da Faculdade de Medicina da Bahia. Bahia: [s. n.], 1872. De acordo com recenseamento de 1872, a população da Salvador era de aproximadamente 129.109 habitantes sendo a população feminina livre em número de 52.822 e a escrava 8.267, somando ao todo 61.089; enquanto que a masculina era de 68.020. Cf. MATTOSO, K. M. de Q. A Bahia no século XIX. Rio de Janeiro: Nova Fronteira, 1992. p. 91.

38 OATHENÊO: Periódico Scientífico e Literário, Bahia, p. 45, 1859, Este documento é um excelente tratado sobre as doenças mais comuns na cidade do Salvador da primeira metade do século XIX. 
Esta preocupação com a saúde da mulher devia-se ao fato de que o corpo feminino tornava-se alvo de um campo específico da ciência médica em processo de desenvolvimento na segunda metade do século XIX: a ginecologia e a obstetrícia. ${ }^{39}$ Desde a fundação da Escola de Medicina da Bahia, já se notava uma preocupação embrionária com a parturição, pois o documento que criava a Escola de Cirurgia declarava que nela não se ensinaria "a cirurgia propriamente dita, mas a Anatomia como base essencial della e a Arte Obstetricia." ${ }^{40}$ Entretanto, foi, no final do século XIX e início do seguinte, que a obstetrícia passou a ganhar destaque. A atuação de dois médicos "parteiros" da Faculdade de Medicina muito contribuiu para esta mudança. Foras eles o Barão de Itapuan e Climério Cardoso de Oliveira. A partir deles, em Salvador, a parturição passou a ser considerada como um negócio de homem.

Nos anúncios onde o Dr. Climério de Oliveira oferecia os seus serviços, ele intitulava-se parteiro e anunciava atendimento gratuito aos pobres. ${ }^{41}$ Outros médicos também utilizam a mesma estratégia, a exemplo do Barão de Itapuan, ${ }^{42}$ Lydio de Mesquita, ${ }^{43}$ Virgilio Damazio, ${ }^{44}$ Alfredo Brito, ${ }^{45}$ Deocleciano Ramos, ${ }^{46}$ José Pedro de Souza Braga, ${ }^{47}$ Rodrigues Lima ${ }^{48}$ e Américo de Souza Marques ${ }^{49}$ Este mecanismo se constituía num elemento atrativo que o médico utilizava para ganhar a confiança das camadas populares, aquelas que tradicionalmente recorreriam ao auxílio da parteira para tratar de doenças do aparelho geniturinário e para o atendimento ao parto e à criança.

39 No trato deste assunto ver MARTINS, A. P. V. A medicina da mulher: visões do corpo feminino na constituição da obstetrícia e da ginecologia no século XIX. Campinas, 2000. Tese (Doutorado em Medicina).

40 OLIVEIRA, E. de S. Memória histórica da Faculdade de Medicina da Bahia concernente ao ano de 1942. Salvador: Centro Editorial e Didático da UFBA, 1992. p. 76.

41 FUNDAÇÃO Clemente Mariani, Diário de Noticias, p. lii. 1889. Almanch.

42 ARQUIVO Público do Estado da Bahia. Diário de Noticias, Bahia, anno 14, n. 126, p. 1, 26 de maio de 1888 .

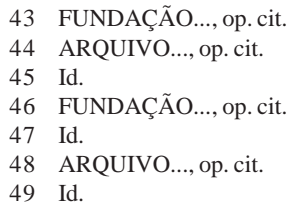


Nesta Bahia, que se modernizava à luz da ciência, todo e qualquer conhecimento pautado apenas no conhecimento empírico-sensorial era rotulado de charlatanismo.

Através do conhecimento do corpo da mulher, os médicos baianos passaram a tentativa de normatização da alma feminina, condenando todo e qualquer hábito que impossibilitasse à mulher de elite o cumprimento do seu papel social de mãe e esposa. A preocupação da elite oitocentista é justificada pela necessidade de formar as futuras lideranças da Nação e cabia às mulheres a tarefa de educar os cidadãos e ativistas políticos do Estado brasileiro. Neste contexto, o discurso médico-higienista passou a condenar os novos hábitos e as formas "mundanas" de socialização urbana, típicos do século XIX, tais como saraus, teatros, bailes, folhetins, romances filosóficos e o vestuário à moda francesa.

Tratando desta temática temos a polêmica obra do Dr. José Lino Coutinho, publicada na Bahia em 1849 - Cartas sobre a educação de Cora, seguidas de um catecismo Moral, Político e Religioso ${ }^{50}$ - que foi um marco na história da educação feminina no Brasil. Trata-se de um texto coerente

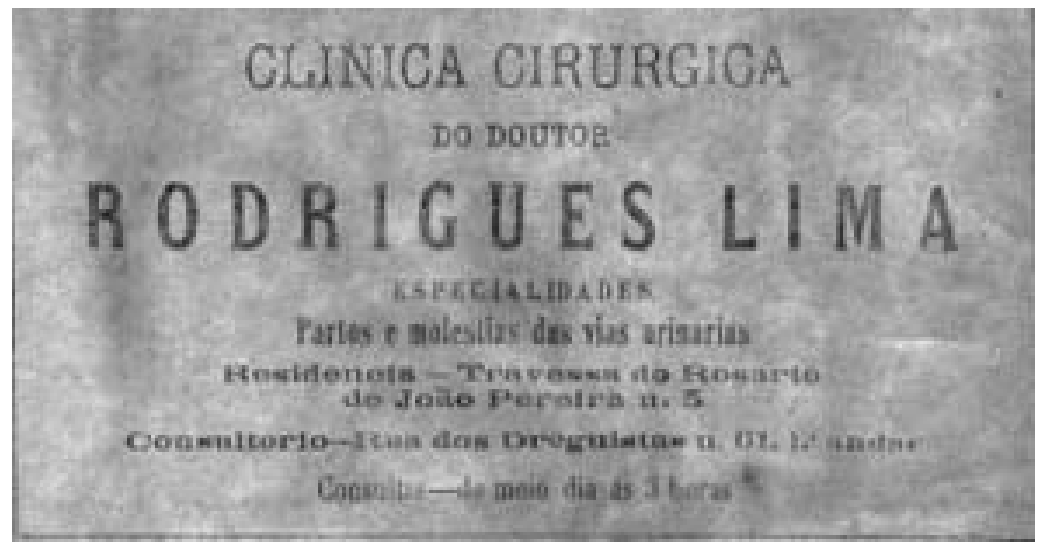

50 Sobre este tratado para educação feminina temos o trabalho de CASTRO, D. D'A. B. de. Cartas sobre a educação de Cora do Dr. José Lino Coutinho. Salvador: Coleção Cardeal da Silva, UCSal, 1977. Ver também, REIS, A. D. Cora: Lições de comportamento feminino na Bahia do século XIX. Salvador: Centro de Estudos Baianos da UFBA, 2000. 
com o projeto de modernização e civilização da sociedade brasileira através da educação "higiênica" para a mulher: esposa e mãe.

As orientações didáticas do Dr. Lino Coutinho ${ }^{51}$ não mudavam o papel social da mulher, mas inovavam nos meios para atingir este fim. Ele pregava a necessidade de ilustração feminina em algumas áreas do saber, tais como aprendizado de História e Ciências Naturais, Língua Portuguesa, Francês, além, é claro, das prendas domésticas. A educação física, os banhos frios e a leitura eram hábitos que deveriam fazer parte do cotidiano da jovem Cora. Estas últimas idéias chocaram a sociedade baiana e não foram poucas as polêmicas travadas em torno das novas práticas, inclusive dentro da própria Faculdade de Medicina, onde alguns médicos se opunham e outros apoiavam as idéias do médico José Lino Coutinho. Todavia, o ideal de corpo saudável e fecundo, casa asseada, vestuário sempre limpo e alinhado, encontrou partidários na Bahia do século XIX.

A preocupação médica também marcava o mundo do trabalho, pois algumas atividades femininas eram consideradas imorais, demonstrando a necessidade de regular os espaços onde houvesse riscos de transgressão dos valores instituídos, a exemplo do que foi publicado na Gazeta Médica a respeito da influência das máquinas de costura sobre a saúde e a moral das mulheres:

\footnotetext{
Parece que não são sem razão as censuras ultimamente feitas contra o uso das machinas de costura. O Dr. Guibort, médico do Hospital de $\mathrm{S}^{\text {ta }}$ Louis, apresenta, como refere o Medical Record, casos de doentes que attribuiam a leuchorrhea, menorrhagia etc..., ao uso destas machinas.

Algumas confessaram que, durante o trabalho, tinham às vezes uma excitação venerea produzida pelo attrito das coxas, e que ás vezes, lhes era preciso suspender este acto. Estas ideias tão razoaveis, e demais, comprovadas pelos factos, merecem seria attenção, e seria conveniente, como suggere o Sr. Guibort, que se empregasse n'estas machinas com outra força motriz que não essa produzida pela acção alternada dos pedaes. ${ }^{52}$
}

51 COUTINHO, J. L. Cartas sobre a educação de cora, seguidas de um Cathecismo moral, político e religioso. Bahia: Typographia de Carlos Poggetti, 1849. FFCH-UFBA.

52 GAZETA MÉDICA DA BAHIA. Salvador, ano 1, n. 24, p. 25, jun. 1867. Microfilmes da 
Neste exercício de normatização do comportamento feminino e do seu corpo, adequando-os aos padrões de civilidade desejável, os médicos não pouparam fôlego e seus olhares higiênicos dirigiram-se para o vestuário feminino. O espartilho, os coletes para modelagem do busto, cintura e quadris foram duramente criticados. O primeiro comprimia a circulação torácica e abdominal, empurrando para a cavidade pélvica o útero e as vísceras do abdômen..$^{53}$ Estas peças, que mais pareciam o "trabalho de um ferreiro que o de uma modesta costureira," 54 foram tidas como causas de abortamento, doenças nervosas, além da esterilidade. ${ }^{55}$ O Dr. Rosalvo Rego, em 1896, fez um apelo pungente para as representantes do "sexo amável":

D'aqui lanço, pois, um brado de condemnação ao uso do espartilho, ao mesmo tempo que um de censura ás gentis representantes do sexo amavel, cuja ambição de beleza as leva, não contentes com a belleza dos seus rostos, a procurarem, embora por um meio prejudicial, a belleza de seus corpos. ${ }^{56}$

Para cumprir o seu papel de mãe e esposa civilizadas, as mulheres grávidas deveriam fugir dos prazeres excessivamente venosos, do ócio, das leituras de romances, dos bailes e teatros, pois estes hábitos poderiam provocar o desgaste físico, levando ao abortamento espontâneo.$^{57}$ Para as donzelas e viúvas, estes entretenimentos também eram nocivos à saúde física e moral, uma vez que estas ficavam expostas a toda sorte de corrupção dos bons costumes, levando-as a sofrer de ninfomania, histeria e hipocondria. ${ }^{58}$

53 BAHIA, B. da S. Considerações acerca do abortamento. In: Memorial de medicina brasileiro. Salvador: Imprensa Econômica, 1885, p. 13. (These defendida na Escola de Medicina da Bahia).

54 VIANA, J. T. F. L. Breves considerações sobre o aleitamento. In: Memorial de medicina brasileiro. Salvador: Typographia de Epifânio Pedroza, 1853. p. 29. (These defendida na Escola de Medicina da Bahia).

55 RIBEIRO, M. C. Considerações acerca do abortamento. In: Memorial de medicina brasileiro. Salvador: Imprensa Econômica, 1883. p. 4-5. (These defendida na Escola de Medicina da Bahia).

56 REGO, R. Da esterilidade da mulher. In: Memorial de medicina brasileiro. Salvador: Typographia e Encadernação do Diário da Bahia, 1896. p. 45. (These defendida na Escola de Medicina da Bahia).

57 RIBEIRO, op. cit., p. 4-5.

58 Ver CASTRO, D. A mulher submissa. Teses da Faculdade de Medicina da Bahia no século XIX. Salvador: Press Color, 1996. 
Na cidade do Salvador, o corpo e a saúde da mulher foram temas amplamente discutidos na segunda metade do século XIX pela comunidade médica. O interesse pelo corpo feminino estava revestido de ideais normatizadores, identificados como desdobramento da "missão civiliza-dora" da nação brasileira, projetando, assim, outros padrões de comportamento feminino, quer no espaço doméstico, quer no de lazer, no de trabalho e nas vias públicas.

\section{Comadres: companheiras da gravidez ao batismo}

No acompanhamento da gravidez, do parto e do "resguardo"59, essas comadres punham em prática um arsenal de procedimentos técnicos desveladores dos valores religiosos, morais, comportamentais, o que por conseguinte, representa uma nuance da multifacetada forma de apropriação da cultura do corpo na sociedade baiana.

Belinha, parteira de profissão, que desconfiava dos médicos, principalmente dos "franguinhos de botica", aparou meninos desde os onze anos de idade e, com a sua vasta experiência, aconselhava a mulher prenha a não parar em porta de enterro para não correr o risco de morrer de parto; não era bom cruzar as pernas e os braços, pois estes hábitos amarravam o parto; deixar as pernas dependuradas causava inchaço que deveria ser combatido com escalda-pé de água com sal; comer pimenta não era aconselhável, porque é quente e a criança nasce com hemorróidas; dar nós no cordão da anágua era um perigo, pois o cordão umbilical podia enrolar no pescoço do menino. Na hora do parto, caso a criança estivesse em má posição, passava-se uma fita verde em volta da barriga da mulher, sem dar nó e rezava-se:

Verde foi a esperança que levou São José, Maria Santíssima e Senhor Menino ao Egito.

Verde foi o campo onde Jesus Homem caminhou.

59 Período pós-parto, também conhecido na literatura médica como puerpério. 
Verde foi o manto de Maria quando chorou a morte de seu filho amado.

Verde foi o cordão que puxou o badalo do sino de São Pedro. Assim também este cordão verde há de puxar este menino para o lugar que deve, com os poderes de Jesus, Maria e José, com os poderes de São Pedro que nunca jogou rede para não trazer peixe. ${ }^{60}$

Quando a mulher apresentava sintomas como engulho na hora do marido deitar, salivação exagerada e forte desejo, estava grávida de três meses, segundo a parteira Melânia. Esta mulher que se intitulava de "parteira entendida" dizia não querer conversa com médicos e se propunha a ensinar (a quem?) o que não se aprendia nas escolas. Ela também conhecia simpatia e ervas abortivas a exemplo do chá de orelha de pau, mas dizia que "o melhor era todo mundo tomar vergonha e deixá os menino irem pra diante." $" 61$

Para Sinhá Coló, quando a mulher ficava de olhos arriados, olheiras fundas, andando com os pés "espalhando brasas" e abaixando de perna aberta, não restava dúvida: era gravidez. Quando as dores do parto começavam, aconselhava Sinhá que a parturiente forrasse a própria cama com folhas de aroeira para evitar algum ataque ou que "dê o ar". Quando a secundina $^{62}$ demorava de sair, a parida deveria sentar em um urinol com água fervendo para receber todo o vapor, dizendo numa só respiração: salsa, salsa, salsa. Em casos de hemorragia a solução era tomar chá de bananeira do mato. ${ }^{63}$

A dieta pós-parto também estava entre as preocupações das parteiras. Das Dores dizia que mulher de resguardo deveria comer alimentos temperados com salsa em lugar de coentro; se fosse viciada em comer mo-

60 Belinha chamava-se Maria Isabel da Hungira, partejava desde os 11 anos no interior da Bahia, em Catete, município de Irará. Cf. VIANNA, H. As aparadeiras e as sendeironas: seu folclore. Salvador: Centro de Estudos Baianos da Universidade Federal da Bahia, 1988. p. 11- 21. Passim.

61 Melânia Margarida dos Santos, residente em Coutos, subúrbio de Salvador, aprendeu a partejar com o pai que aparava as crianças da família. Cf. VIANNA, op. cit., p. 10-19. Passim.

62 Nome dado à placenta.

63 Clotilde Serapina das Virgens, conhecida por Sinhá Colo, aprendeu a aparar menino na "roça", vendo as mulheres parindo e conversando com gente entendida, como o Dr Jambeiro, médico da cidade de Casto Alves. Além desta cidade do interior da Bahia, transitou por outras como Serrinha, Uauá, Itaberaba, Jequiré, Barracão, Pedra Branca, Andaraí e Jaguaquara. Cf. VIANNA, op. cit., p. 10-23. Passim. 
lho, a pimenta deveria ser ralada com o talo; o escaldado de galinha devia ser preparado com quiabo sem caroço. Outros cuidados a parida devia ter durante o seu resguardo, principalmente com o sereno entre seis e oito horas da noite; a roupa teria que ser passada a ferro na hora de usar e mulher "de lua" ${ }^{64}$ não deveria se sentar em cama de parida. ${ }^{65}$

Ernestina não concordava com um resguardo tão rigoroso, dizia que ter menino não era doença e os cuidados deveriam ser tomados durante a gravidez. Todavia não dispensava alguns conselhos para a mulher parida, como segurar o seio quando estivesse dando mama para evitar a flacidez e, nos intervalos da amamentação, a mulher deveria passar pasta de tanino de bananeira e talco de Veneza. ${ }^{66}$

Sofia afirmava que, "depois de cortar o umbigo da criança, fazia o procedimento da "cura" com mertiolate, mas dizia não custar nada pegar o pó do chinelo do pai, bem torrado e peneirado, fazer um parche que nem um curativo e colocar no umbigo do nenê"; barro de parede torrado e peneirado também era utilizado. A tesoura usada no corte do umbigo, depois de limpa, deveria ficar de pernas abertas embaixo da cama nas primeiras 24 horas após o parto. ${ }^{67}$

Diante de tantos conselhos e cuidados com a parturiente e com o recém-nascido, é compreensível o porquê dessas mulheres serem chamadas de comadres pela população. Durante muitos anos, ostentar este título era uma honra e significava prestígio e reconhecimento na comunidade onde atuavam, o que lhes permitia carregar a criança que elas trouxeram ao mundo, no dia do batismo, compondo o cortejo junto aos pais, padrinhos e familiares. As parteiras "representavam", ou melhor, apresentavam o recémnascido diante de um dos sacramentos da Igreja: o batismo. ${ }^{68}$ Mais uma vez,

64 Em período menstrual.

65 Maria das Dores Sacramento de Jesus, nasceu em Mata de São João e, aos 5 anos, foi levada para Monte Gordo no intuito de ser iniciada na arte pela Velha Calú, rezadeira, parteira, bordadeira que mantinha uma "casa de mestra". Aos 15 anos, foi para Salvador e fixou-se no Baixão do Matatu de Brotas onde passou a aparar meninos não só na capital como no Recôncavo. Cf. VIANNA, op. cit., p. 9- 26. Passim.

66 Ernestina da Paixão Alves era de Salvador mas vivia em Cruz das Almas, aprendeu a partejar por acaso e fez muito doutor ficar de cara mexendo pois entendia mais do que eles. Cf. VIANNA, op. cit., p. 11- 26.

67 Sofia Magno da Anunciação parteira que nasceu, viveu e partejou no Bairro da Liberdade em Salvador. Cf. VIANNA, op. cit.

68 Depoimento de Monsenhor Gilberto Vaz Sampaio, Pároco da Comunidade de VarzedoBA, em junho/2000. 
tem-se a legitimação da ação das parteiras, pois a Igreja era uma instituição que reconhecia o papel dessas mulheres e sua importância na sociedade, atuando, também, no sentido de preservar o corpo feminino, afastando-o dos olhos e mãos masculinos.

Por que muitas vezes acontece perigarem as mulheres de parto, e outro - sim perigarem as crianças, antes de acabarem de sahir do ventre de suas mães, mandamos as parteiras, que apparecendo a cabeça, ou outra alguma parte da criança, posto que seja mão, ou pé, ou dedo, quando tal perigo houver a baptisem na parte que apparecer, e em tal caso, ainda que ahi esteja homem, deve por honestidade baptizar a parteira, ou outra mulher, que bem o saiba fazer. ${ }^{69}$

A propósito, o costume da parteira levar a criança ao batismo também existiu na Alemanha, conforme o relato da comadre aldeã Lisbeth Burger:

Babeth [a velha parteira] naturalmente andou falando mal pela aldeia, embora tivesse dormido durante todo o parto. Deu-se, porém, por satisfeita quando lhe permittiram carregar a criança para o baptizado e receber, conforme o costume, o presente do padrinho e da madrinha. A mãe de todo não concordava que eu deixasse isso a Babeth. Eu também não estava de accordo, não por causa do presente, mas porque tive sempre tanto gosto em ir ao baptismo, levando "meus filhos". De facto, é sempre um pouquinho meu filho aquelle que eu levo á igreja... ${ }^{70}$

Rastreando uma origem mais remota para o termo comadre, encontrou-se sua utilização desde a Antiguidade Clássica. Ela possuía várias

69 Constituições Primeiras do Arcebispado da Bahia. D. Sebastião Monteiro da Vide. Sinodo Diocesano de 1707; Título XIII: Dos casos, em que se pode administrar o sacramento do baptismo por aspersão, fóra da Igreja, em qualquer lugar, e por qualquer pessoa. São Paulo: Tipografia 2 de Dezembro, 1853, Livro I.

70 BURGER, L. Entre leito e berço: memórias de uma parteira. Petrópolis: Vozes, [19-]. p. $31-32$ 
responsabilidades, tais como acompanhamento da "delivrance", ${ }^{71}$ corte do cordão umbilical da criança, orientação à parturiente quanto ao aleitamento, dentre outras atividades. ${ }^{72}$ Em comunidades rurais da Península Ibérica e do Brasil, o termo também foi utilizado para designar a parteira prática, sem diploma. Estas mulheres eram muito respeitadas no seio de suas comunidades, pois eram as responsáveis por acompanhar o nascimento e ajudar a parturiente em momentos de grande dor e aflição.

A partir do final do século XVIII e início do XIX, o termo comadre vai ganhando, na Europa, um caráter nitidamente depreciativo, do qual não se furta o Brasil visto que possuía no Velho Mundo sua matriz inspiradora de modelo civilizatório, principalmente na França. A alcunha de comadre passou a categorizar mulheres ignorantes, embora muito solicitadas, localizadas do lado de lá da civilização, uma lembrança indesejável, mas persistente. Aquelas, que outrora foram imprescindíveis em momentos de vida e morte, passaram a ser seladas com a etiqueta do atraso e da ignorância, não mais compatíveis com a aurora dos novos tempos.

Pelas vielas esconsas, não raro, encontravam-se grandes cruzes brancas, sobre as portas das casas. Sinal de residências de parteiras, aparadeiras, solícitas, mas ignorantes comadres. ${ }^{73}$

A fala dos médicos baianos sobre as comadres é de palpável desprezo e estas eram constantemente acusadas de agravar o estado de saúde das mulheres de Salvador que, ao invés de procurarem o auxílio médico, recorriam à "indigna comadre" que ordinariamente agravava o mal das enfermas. ${ }^{74}$

Durante a Colônia e o Império, os médicos não eram profissionais de grande prestígio, pois a população não acreditava nos processos de cura empregados por estes e buscava os cuidados das parteiras, curandeiros, rezadores, sangradores e demais profissionais da medicina popular. Pode-

71 Expulsão da placenta.

72 SILVA, A. A primeira médica do Brasil. Rio de Janeiro: Pongetti, 1954. p. 14.

73 EDMUNDO, L. $O$ Rio de Janeiro no tempo dos vice-reis. Rio de Janeiro: Instituto Histórico e Geográfico Brasileiro, 1932. p. 478.

74 MICROFILMES DA FFCH-UFBA. O Athenêo: Periódico Scientífico e Literário, Bahia, 1850 , p. 45 
se deduzir da literatura oitocentista, a priore, que estas crenças na terapêutica popular estavam reservadas exclusivamente às pessoas iletradas, pertencentes aos estratos inferiores da sociedade. Todavia esta generalização não é de todo verdadeira para a sociedade baiana, pois as fontes que não falam diretamente sobre o saber médico, mas que o revelam, permitem fazer um contraponto com o discurso oficial da medicina e tecer uma rede de significados mais amplos no que tange à atuação e importância dos "leigos" na medicina baiana e, em especial, da participação das mulheres neste processo. $^{75}$

A correspondência do Desembargador João Rodrigues de Britto, circulante na Bahia em 1807 e publicada pela Imprensa Nacional de Lisboa em 1821 sob o título Cartas Econômico-políticas sobre a agricultura e comércio da Bahia, traz uma defesa da quebra do monopólio dos médicos, cirurgiões e boticários no trato das doenças, bem como reconhece o êxito do "sexo feminino" no campo da saúde. O argumento utilizado pelo autor aponta para a defesa do livre mercado e da concorrência como fator de melhoria dos serviços.

Póde-se enumerar-se entre as causas que obstão á povoação do paiz, o monopolio que logrão os Medicos, Cirurgiões e Boticarios.

Porque elle concentrando em hum pequeno numero de pessoas o exercicio destas artes, difficulta a diffusão das luzes habilitando os officiais de saude para fazer o que se chama carrapata [de cura demorada], e dispensando-os do trabalho de estudarem até por falta de tempo. Permitti o tratar dos enfermos a todos os que tiverem para isso inclinação, e vós vereis hum grande numero de homens de letras, e curiosos, applicarem-se á arte de curar, pôrem-se em estado de discernir os charlatães, e obriga-los pela sua concurrencia a estudarem, e cuidarem seriamente dos seus doentes. O Boticario, diz Smith, he o Medico do pobre. Os nossos Parocos o seriam também, se a Lei lhes não inhibisse huma pratica bem digna da caridade christã. Elles sabem ao menos ler, e escrever, o que sempre se encontra nos que obtiverão cartas d'exame e licenças para

75 Vide BITTENCOURT, A. R. de G. Longos serões do campo. Rio de Janeiro: Nova Fronteira, 1992. v. 1 e 2. 
curarem, alias cartas de seguro para matarem impunimente pela cega confiança, que o povo sincero pões em semelhantes cartas, que, a não serem ellas, averiguaria a capacidade dos Cirurgiões a quem se entregasse. São bem conhecidos alguns lavradores do Reconcavo, que por caridade curão muita gente com feliz sucesso, como o Senhor do Engenho do Pouco Ponto, e há mesmo dentro da cidade algumas pessoas do sexo feminino, que exercem a Pharmacia com mais perfeição que muitos Boticarios encartados, as meninas do Senhor João Ladislau, cuja botica he a mais acreditada. ${ }^{76}$

As "meninas do Sr Ladislau" - João Ladislau Figueredo de Melo, chamavam-se Joana, Rosa e Ana. Estas mulheres receberam Cartas de Farmacêutico em 20 de agosto de $1811 .{ }^{77}$ Considera-se que a inserção feminina nas atividades da cura suscita muitas outras investigações, principalmente no que toca a história da Capitania e Província da Bahia, pois o número de pesquisadores que se dedicam a esta temática, ainda é muito reduzido.

Foi somente na segunda metade do século XX que os médicos angariaram a simpatia e confiança do público feminino, resultado num fruto de uma tessitura construída ao longo do século XIX. Todavia a presença do doutor na cena do parto, ou da parturiente nos hospitais e maternidades, não excluiu totalmente a influência da parteira no lugar do nascimento. Elas podem ser encontradas em todo o território brasileiro, principalmente nas regiões onde a população é desassistida dos cuidados médicos, ou preferem manter a tradição dos ancestrais.

Em pleno ingresso no século XXI, podem-se encontrar comadres, como a índia Dórica, no Amapá, ensinando que "parteira não tem escolha, é chamada nas horas mortas da noite para povoar o mundo", ${ }^{78}$ esperando o tempo do menino nascer.

76 Este documento originou-se de um ofício que o Conde da Ponte enviou ao Senado da Câmara da Bahia em 1807. Cf. BENVINDES, I. A. F. Cartas econômico-políticas sobre a agricultura e comércio da Bahia. Lisboa: Imprensa Nacional, 1821. p. 57-58.

77 CALMON, P. A bala de ouro: história de um crime romântico. 2. ed. Salvador: Academia de Letras da Bahia, 1998. Nota de rodapé, p. 41.

78 BRUM, E.; ADAMS, D. A floresta das parteiras. Época, p. 82-83, 27 mar. 2000. 
O Brasil urbano pouco escuta a voz das parteiras porque desacostumou o ouvido em relação aos sons do conhecimento de outrora. As parteiras do Amapá, como tantas outras deste Brasil de ontem e de hoje, são mulheres "emersas dos confins de outras mulheres com o dom de pegar criança. (...) É sabedoria que não se aprende, não se ensina nem mesmo se explica. Acontece apenas. Esculpidas por sangue de mulher e água de criança." 79

\section{Referências}

ARQUIVO Público do Estado da Bahia. Diário de Notícias, Bahia, anno 14, n. 126, p. 1, 26 maio 1888.

ATHAIDE, J. L. de. La Ville de Salvador au XIXe Siècle - aspects démographiques. Paris, 1975. These (Doutorado) - L'Université de Paris X.

BENVINDES, I. F. Cartas econômico-políticas sobre a agricultura e comércio da Bahia. Lisboa: Impresa Nacional, 1821. p. 57-58.

BITTENCOURT, A. R. de G. Longos serões do campo. Rio de Janeiro: Nova Fronteira, 1992. v. 1 e 2.

BRUM, E.; ADAMS, D. A floresta das parteiras. Época, p. 82-83, mar. 2000.

BURGER, L. Entre o leito e o berço: memórias de uma parteira. Petrópolis: Vozes, [18-]. p. 31-32.

CALMON, P. A bala de ouro: história de um crime romântico. 2. ed. Salvador: Acadademia de Letras da Bahia, 1998. Nota de rodapé, p. 41.

CASTRO, D. A mulher submissa. Teses da Faculdade de Medicina da Bahia no século XIX. Salvador: Press Color, 1996.

CASTRO, D. D’A. B. de. Cartas sobre a educação de Cora do Dr. José Lino Coutinho. Salvador: Coleção Cardeal da Silva; U CSal, 1977. 
CONSTITUIÇÕES PRIMEIRAS DO ARCEBISPADO DABAHIA. São Paulo: Tipografia, 2 dez. 1853. Livro I.

DEL PRIORE, M. A árvore e o furto: um breve ensaio sobre o aborto. [S. 1.: s. n.], 2000.

. A mulher na história do Brasil. São Paulo: Contexto, 1994. p. 51. . Ao sul do corpo: condição feminina, maternidade e mentalidade no Brasil Colônia. Rio de Janeiro: José Olympio, 1993.

. Dossiê: a história do corpo. Anais do Museu Paulista, São Paulo, v. 3, p. 14-15, jan./dez. 1995.

. História das mulheres: as vozes do silêncio. In: FREITAS, M. C. (Org.). Historiografia brasileira em perspectiva. São Paulo: Contexto, 1998.

DUBY, G. Damas do século XII: a lembrança dos ancestrais. São Paulo: Companhia das Letras, 1997.

EDMUNDO, L. O Rio de Janeiro no tempo dos vice-reis. Rio de Janeiro: Instituto Histórico e Geográfico Brasileiro, 1932. p. 478.

FOUCAULT, M. O nascimento da clínica. Rio de Janeiro: Forense Universitária, 1998. p. 12.

FRANCO JÚNIOR, H. As utopias medievais. São Paulo: Brasiliense, 1992. FUNDAÇÃO Clemente Mariani. Diário de Notícias, Bahia, p. lii, 1889.

GAZETA Médica da Bahia, Salvador, ano 11, n. 1, p. 6, jan. 1879.

GAZETA Médica da Bahia, Salvador, ano 1, n. 24, p. 25, jun. 1867. Microfilmes da FFCH-UFBA.

MACEDO, J. R. de. A mulher na Idade Média. São Paulo: Contexto, 1997.

MARTINS, A. P. V. A medicina da mulher: visões do corpo feminino na constituição da obstetrícia e da ginecologia no século XIX. Campinas, 2000. Tese (Doutorado em Medicina).

MATTOSO, R. M. de Q. A Bahia no século XIX. Rio de Janeiro: Nova Fronteira, 1992. 
MEMORIAL de medicina brasileiro. Índice dos graduados da Faculdade de Medicina da Bahia. Bahia: [s. n.], 1872.

O ATHENÊO: Periódico Scientífico e Literário, Bahia, 1850.

OLIVEIRA, E. de S. Memória histórica da Faculdade de Medicina da Bahia concernente ao ano de 1942. Salvador: Centro Editorial o Didático da UFBA, 1992.

OLIVEIRA, O. de. O fetichismo terapêutico e a medicina moderna. In: VIANNA, G. Olinto de Oliveira. Porto Alegre: Globo, 1945. p. 45.

PATERSON, J. L. Gazeta Médica da Bahia, Salvador, ano 10, n. 5, p. 202, maio 1878.

PONTES, K. V. Mulados: políticos e rebeldes baianos. Salvador, 2000. Dissertação (Mestrado em História) - Faculdade de Ciências Humanas da Universidade Federal da Bahia.

REIS, A. D. Cora: lições de comportamento feminino na Bahia do Século XIX. Salvador: Centro de Estudos Baianos da UFPA, 2000.

REIS, J. J. A morte é uma festa: ritos fúnebres e revolta popular no Brasil do século XIX. São Paulo: Companhia das Letras, 1991.

SANTACASADE MISERICÓRDIADA BAHIA. Relatórios de 1871. Bahia, mapa 3.

SANTACASA DE MISERICÓRDIADA BAHIA. Relatórios de 1880. Bahia, p. 4.

SANTA CASA DE MISERICÓRDIA DA BAHIA. Livro $19 .^{\circ}$ de assentos de pessoas (1852-1855).

SÃO PAULO, F. Linguagem médica popular no Brasil. Salvador: Itapuã, 1970. v. 2, p. 223-224.

SILVA, A. A primeira médica no Brasil. Rio de Janeiro: Pongetti, 1954. p. 14.

SCHWARC, L. M. O espétáculo das raças: cientistas, instituições e questão racial no Brasil - 1870-1930. São Paulo: Companhia das Letras, 1993.

SOARES, C. M. Mulher negra na Bahia do século XIX. Salvador, 1994. 
Dissertação (Mestrado em História) - Faculdade de Filosofia e Ciências Humanas da Universidade Federal da Bahia.

SOUZA JÚNIOR, C. M. Histórico dos hospitais e maternidades. Bahia: Imprensa Econômica, 1886.

VIANNA, H. As aparadeiras e sendeironas: seu folclore. Salvador: Centros de estudos Baianos da Universidade Federal da Bahia, 1988. 